\title{
THÀNH PHẦN LOÀI VÀ PHÂN BỐ CỦA RONG BIỂN Ở ĐẦM NẠI - TỈNH NINH THUẬN
}

\author{
Đàm Đức Tiến \\ Viện Tài nguyên và Môi truờng biển-Viện Hàn lâm Khoa học và Công nghệ Việt Nam \\ E-mail: tiendd@imer.ac.vn
}

Ngày nhận bài: 1-9-2015

\begin{abstract}
TÓM TĂT: Kết quả nghiên cứu về rong biển đầm Nại tỉnh Ninh Thuận của đề tài: "Nghiên cứu giải pháp phục hồi hệ sinh thái đầm, hồ ven biển đã bị suy thoái ở khu vục miền Trung”, Mã số KC.08.25/11-15 trong hai năm (2013 và 2014) tại 12 điểm khảo sát đã chỉ ra rằng, tại đầm Nại hiện có 47 loài rong biển, thuộc 4 ngành là rong lam (Cyanophyta), rong đỏ (Rhodophyta), rong nâu (Phaeophyta) và rong luc (Chlorophyta). Trong số đó, rong lam có 5 loài, chiếm 10,6\% tổng số loài; rong đỏ có 15 loài chiếm 31,9\%; rong nâu có 5 loài, 10,6\% và nhiều nhất là rong luc có 22 loài chiếm 46,9\% tổng số loài. Số luợng loài tại các điểm nghiên cưu dao động trong khoảng 3 loài/điểm (điểm 17) đến 20 loài/điểm (điểm 6) và trung bình là 11,3 loài/điểm. Về mùa khô có 38 loài và mùa mura có 39 loài (có 32 loài xuất hiện cả trong mùa mua và mùa khô). Hệ số tuoong đồng tại các điểm nghiên cúu dao động tù 0,1 (giữa điểm 11 và 17) đến 0,82 (giũa điểm 14 và 17) và trung bình là 0,28 . Trong số 47 loài, có 31 loài phân bố trên vùng triều và 32 loài ở vùng duoói triều. Khu hệ rong biển đầm Nại mang tính nhiệt đới.
\end{abstract}

Tù khóa: Đầm Nại, loài, phân bố, thành phần, rong biển.

\section{MỞ ĐẦU}

Rong biển là một nhóm thực vật bậc thấp sống ở biển, đây là một hợp phần quan trọng của tài nguyên biển. Rong biển chẳng những là một nguồn tài nguyên quan trọng, có giá trị kinh tế từ lâu đã được con người sử dụng trong các lĩnh vực của cuộc sống mà còn là đối tượng có ý nghĩa rất lớn trong nghiên cứu lý luận.

Đầm Nại thuộc địa phận huyện Ninh Hải, tỉnh Ninh Thuận. Bắc giáp Tân Hải (thôn Gò Đền), tây bắc giáp Hộ Hải (thôn Lương Cách, Hộ Diêm), đông và đông bắc giáp Phương Hải (thôn Phương Cựu), đông nam giáp Tri Hải (thôn Tri Thủy), nam và tây nam giáp Khánh Hải (thôn Dư Khánh). Đầm có dạng lòng chảo nông, hình lục giác không đều, nối với biển qua lạch Ninh Chữ dài 2 km, rộng 150 - 300 m, sâu 3 - $5 \mathrm{~m}$, chỗ hẹp nhất $140 \mathrm{~m}$ tại cầu Tri Thủy.
Diện tích lòng đầm Nại khoảng 700 ha, vùng đồng bằng ven đầm bị thủy triều chi phối trên 400 ha [1].

Bài báo giới thiệu về thành phần loài và phân bố của rong biển đầm Nại thuộc tỉnh Ninh Thuận, là một trong những nôi dung nghiên cứu của đề tài: "Nghiên cứu giải pháp phục hồi hệ sinh thái đầm, hồ ven biển đã bị suy thoái ở khu vực miền Trung", Mã số KC.08.25/11-15.

\section{TÀI LIÊUU VÀ PHƯƠNG PHÁP NGHIÊN CứU}

\section{Tài liệu}

Gồm mẫu của các loài rong biển thu được qua 3 chuyến khảo sát vào mùa mưa và mùa khô (tháng 7/2013 và tháng 5/2014) của đề tài "Nghiên cứu giải pháp phục hồi hệ sinh thái đầm, hồ ven biển đã bị suy thoái ở khu vực miền Trung", Mã số KC.08.25/11-15, tại 12 
Thành phần loài và phân bố của rong biển ...

điểm (số thứ tự 1, 2, 6, 7, 9, 11, 13, 14, 15, 17, 18 và 20$)$ (hình 1$)$.

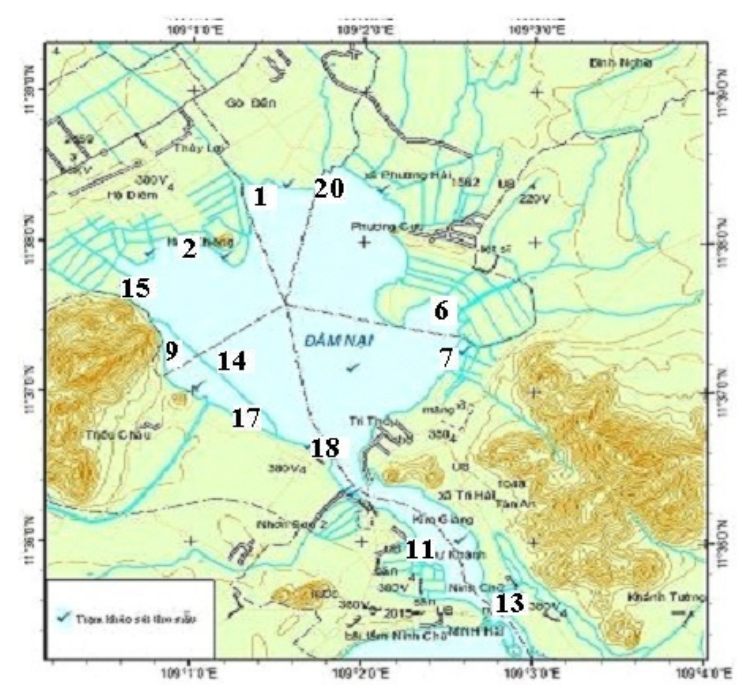

Hình 1. Sơ đồ khu vực và các điểm khảo sát

\section{Phương pháp điều tra ngoài thực địa}

Việc khảo sát thu mẫu rong biển trên vùng triều dựa vào Quy phạm tạm thời điều tra tổng hợp biển (phần Rong biển) của Uỷ ban Khoa học và Kỹ thuật Nhà nước ban hành năm 1981 [2]. Khảo sát vùng dưới triều dựa vào tài liệu hướng dẫn của English và nnk., [3] bằng thiết bị lặn SCUBA, máy chụp ảnh dưới nước hiệu OLYMPUS kỹ thuật số (sản xuất tại Nhật Bản).

Mẫu rong tươi sau khi thu, được ngâm trong dung dịch formol 5\%, mẫu khô (tiêu bản) được đặt trên giấy Croki sau đó ép trong giấy thấm và làm khô tự nhiên, định dạng mẫu vật.

\section{Phương pháp nghiên cứu trong phòng thí nghiệm}

\section{Xác định thành phần loài}

Mẫu vật được phân tích trong phòng thí nghiệm của Phòng Sinh thái và Tài nguyên Thực vật biển, Viện Tài nguyên và Môi trường biển (Viện Hàn lâm Khoa học và Công nghệ Việt Nam). Việc định loại chủ yếu dựa vào các tiêu chuẩn về hình thái ngoài và cấu tạo trong (các tiêu bản lát cắt dưới kính hiển vi Leica với độ phóng đại 150 lần). Việc phân loại rong biển tuân theo các nguyên tắc chung của phân loại thực vật. Tài liệu định loại căn cứ vào các tác giả trong và ngoài nước [4-7].

\section{Nghiên cứu phân bố}

\section{Phân bố thẳng đứng (phân bố sâu)}

Việc nghiên cứu phân bố thẳng đứng của rong biển dựa vào nguyên tắc phân chia vùng triều của Feldmann (1937) [8] và Phạm Hoàng Hộ (1962) [9]. Theo cách phân chia của các tác giả nói trên, phần ven biển bao gồm các vùng khác nhau dựa vào mực thuỷ triều, bao gồm triều cao, triểu giữa và triều thấp. Mực nước, căn cứ vào chế độ thủy triều tại Cam Ranh, tháng 7/2013 và tháng 5/2014 [10,11].

\section{Phân bố địa lý của rong biển (phân bố rộng)}

Phân bố rộng được hiểu theo nghĩa phân bố rộng trong không gian theo chiều nằm ngang của rong biển. Để nghiên cứu sự phân bố địa lý của rong biển, chúng tôi đã sử dụng chỉ số tương đồng Sorrensen (S).

$$
\mathrm{S}=2 \mathrm{C} /(\mathrm{A}+\mathrm{B})
$$

Trong đó: $\mathrm{A}$ là số loài tại điểm $\mathrm{A}, \mathrm{B}$ là số loài tại điểm $\mathrm{B}, \mathrm{C}$ là số loài chung giữa hai điểm $\mathrm{A}$ và $\mathrm{B}$.

Khi giá trị của hệ số càng gần 1 thì sự tương đồng càng lớn, khi càng gần 0 thì sự tương đồng càng thấp.

Các số liệu này được đưa vào các hàm của Excel để tính toán cho ra kết quả cuối cùng.

Khu hệ rong biển được tính toán dựa trên chỉ số Cheney. Khi chỉ số này < 3 là khu hệ á nhiệt đới; nằm trong khoảng 3 - 6 là hỗn hợp và $>6$ là nhiệt đới [12].

\section{KẾT QUẢ VÀ THẢO LUẬN}

\section{Thành phần loài}

Qua việc phân tích các mẫu rong biển thu được qua các đợt khảo sát thực địa mùa mưa và mùa khô (tháng 7/2013 và tháng 5/2014) và tham khảo các nguồn tài liệu đã được công bố, chúng tôi đã xác định được 47 loài rong biển, thuộc 4 ngành là tảo lam (Cyanobacteria), rong đỏ (Rhodophyta), rong nâu (Ochrophyta) và rong lục (Chlorophyta). Trong số đó tảo lam có 5 loài, chiếm $10,6 \%$ tổng số loài; rong đỏ có 15 loài chiếm $31,9 \%$; rong nâu có 5 loài, $10,6 \%$ và nhiều nhất là rong lục có 22 loài chiếm $46,9 \%$ tổng số loài (bảng 1). 
Bảng 1. Thành phần loài và phân bố của rong biển ở đầm Nại

\begin{tabular}{|c|c|c|c|c|c|c|c|c|c|c|c|c|c|c|c|}
\hline \multirow[t]{2}{*}{ TT } & \multirow[t]{2}{*}{ Tên taxon } & \multicolumn{12}{|c|}{ Phân bố rộng } & \multicolumn{2}{|c|}{$\begin{array}{c}\text { Phân } \\
\text { bố sâu }\end{array}$} \\
\hline & & 1 & 2 & 6 & 7 & 9 & 11 & 13 & 14 & 15 & 17 & 18 & 20 & VT & DT \\
\hline \multicolumn{16}{|c|}{ CYANOPHYTA } \\
\hline 1 & Aphanocapsa litoralis Hansgrig. & $t^{*}$ & & & & $t^{*}$ & & & & & & & & + & + \\
\hline 2 & Microcystis Reinboldii (Richier) Forti. & $t^{*}$ & & & & $+^{*}$ & & & & & & & & + & \\
\hline 3 & Symploca hydnoides Kuetz. & & & & $+^{*}$ & & & & + & + & & & & + & \\
\hline 4 & Lyngbya aestuarii Liebm. & $t^{*}$ & & & $+^{*}$ & $+^{*}$ & & & & & & & & + & \\
\hline \multicolumn{16}{|c|}{ RHODOPHYTA } \\
\hline 6 & Actinotrichia fragilis (Forsk.) Boergs. & & & & & + & & $t^{*}$ & & & & & & + & + \\
\hline 7 & Galaxaura fastigiata Dcne. & & & & & + & & & & & & & & & + \\
\hline 8 & Pterocladia parva Dawson. & & & & & + & & & & & & & & + & + \\
\hline 9 & Hypnea pannosaJ. Ag. & & & & & + & & & & & & & & & + \\
\hline 10 & Gracilaria gigas Harv. & $t^{*}$ & $t^{*}$ & & * & + & & & & & + & & & & + \\
\hline 11 & G. salicornia (C. Ag.) Dawson. & $t^{*}$ & & * & $+^{*}$ & & & & & & + & & + & & + \\
\hline 12 & G. arcuata Zanard. & & & * & & & & & & & & & & & + \\
\hline 13 & G.eucheumoides Harv. & & & * & & & & & & & & & & + & + \\
\hline 14 & G. tenuispititata Zhang et Xia. & $t^{*}$ & $t^{*}$ & $t^{*}$ & $+^{*}$ & $t^{*}$ & $+^{*}$ & $+^{*}$ & $+^{*}$ & $+^{*}$ & $+^{*}$ & $+^{*}$ & $+^{*}$ & & + \\
\hline 15 & G. bangmeiana Zhang et Xia. & & & * & & & & & & & & & & & + \\
\hline 16 & Centroceras clavulatum (Ag.) Mont. & & & * & & & & & & & & & & + & \\
\hline 17 & Ceramium huysmansii W. V. Bosse. & & & * & & & & & & & & & & + & \\
\hline 18 & C. howei W.V.Bosse. & & & * & & & & & & & & & & + & \\
\hline 19 & Champia parvula (C. Ag.) Harv. & & & & & + & & * & & & & & & + & \\
\hline \multicolumn{16}{|c|}{ PHAEOPHYTA } \\
\hline 21 & $\begin{array}{l}\text { Feldmannia irregularis (Kuetz.) } \\
\text { Hamel. }\end{array}$ & $t^{*}$ & & + & & & & & & & & & & & + \\
\hline 22 & Giffordia Mitchellae (Harv.) Hamel. & $t^{*}$ & & & & & & & & & & & + & & + \\
\hline 23 & Dictyota patens J. Ag. & & & + & & & $t^{*}$ & & & & & & & & + \\
\hline 24 & D. dichotoma (Huds.) Lamx. & & & $t^{*}$ & & & $t^{*}$ & & & & & & & & + \\
\hline \multirow{2}{*}{\multicolumn{16}{|c|}{$\begin{array}{l}25 \\
\text { D. Inalcasonder. } \\
\text { CHLOROPHYTA }\end{array}$}} \\
\hline & & & & & & & & & & & & & & & \\
\hline 26 & Monostroma nitidumWittrock. & + & & & & & & & & + & & & & & + \\
\hline 27 & Enteromorpha torta (Mert.) Reinb. & * & + & $t^{*}$ & + & & $t^{*}$ & & & $+^{*}$ & & & & + & + \\
\hline 28 & E. compressa (L.) Grev. & & + & + & + & & & & & & & & & & \\
\hline 29 & E. kylinii Bliding. & & & & & & & & & & & & $t^{*}$ & + & \\
\hline 30 & E. clathrata (Roth.) Grev. & + & & & & & & & & & & & & + & \\
\hline 31 & Ulva lactucaLinaeus. & & & & & + & & & + & & + & + & & + & + \\
\hline 32 & U. conglobata Kjellm. & & & & & + & & & + & & + & + & & + & + \\
\hline 33 & Chaetomorpha aerea (Dillw.) Kuetz. & * & + & * & $+^{*}$ & & & & & & & & & + & + \\
\hline 34 & $\begin{array}{l}\text { Chaetomorpha antenrina (Boerg.) } \\
\text { Kuetz }\end{array}$ & $t^{*}$ & + & * & $+^{*}$ & & & & & & & & & & + \\
\hline 35 & $\begin{array}{l}\text { Cladophora perpusilla Skottsberg and } \\
\text { Levring. }\end{array}$ & & & $+^{*}$ & & $+^{*}$ & & & & * & + & & & + & \\
\hline 36 & Cladophora insertaDickie. & & & $t^{*}$ & & $t^{*}$ & $t^{*}$ & & & * & & & & + & + \\
\hline 37 & Valonia ventricosa J. Ag. & & & & & * & & & & & & & & + & + \\
\hline 38 & Boodlea composite (Harv.) Brand. & $t^{*}$ & $t^{*}$ & * & & & & & & & + & & & + & + \\
\hline 39 & B. struveoides Howe. & $t^{*}$ & * & & & & & & & & + & & & + & \\
\hline 40 & $\begin{array}{l}\text { Struvea anastomosans (Harv.) } \\
\text { Piccorne. }\end{array}$ & & & & & + & & & & & $+^{*}$ & & & + & + \\
\hline 41 & Microdictyon okamurai Setch. & & & & & & & & & & $t^{*}$ & & & + & \\
\hline 42 & Caulerpa verticillata J. Ag. & * & $t^{*}$ & & * & & & & * & & & & * & + & + \\
\hline 43 & C. vickersiae Boerges. & $t^{*}$ & $t^{*}$ & & * & & & & $+^{*}$ & & & & * & + & + \\
\hline 44 & C. fastigiata Mont. & & & & & & & & $+^{*}$ & * & & + & & + & + \\
\hline 45 & Avrainvillea erecta (Ber.) Gepp. & & & & & & & & $+^{*}$ & & + & * & & + & + \\
\hline 46 & A. lacerate Agardh & & & & & + & & & $+^{*}$ & & + & $+^{*}$ & & + & + \\
\hline 47 & Udotea javensis (Mont.) Gepp. & & & & & & & & $+^{*}$ & & + & $+^{*}$ & & & + \\
\hline Tổn & g số loài: 47 & 18 & 11 & 20 & 12 & 18 & 5 & 4 & 11 & 8 & 14 & 8 & 7 & & \\
\hline Tổn & g số loài mùa khô & 15 & 10 & 10 & 10 & 17 & 5 & 3 & 10 & 5 & 14 & 7 & 4 & 31 & 32 \\
\hline Tổn & g số loài mùa mưa & 15 & 7 & 17 & 11 & 8 & 5 & 4 & 8 & 5 & 3 & 5 & 5 & & \\
\hline
\end{tabular}

Ghi chú: 1, 2, 6, 7, 9, 11, 13, 14, 15, 17, 18, 20: là các điểm thu mẫu. VT: Vùng triều; DT: Dưới triều; (+) mùa khô; (*) mùa múa. 
So với kết quả nghiên cứu trước đây (36 loài, 1994), số lượng loài rong biển trong các đợt khảo sát (không trùng với thời gian khảo sát ở phần phương pháp) tại đầm Nại nhiều hơn 11 loài [1].

\section{Phân bố}

\section{Phân bố rộng}

Kết quả tại bảng 1 cũng cho thấy, về tổng số, số lượng loài tại các điểm nghiên cứu dao động trong khoảng 3 loài/điểm (điểm 17) đến 20 loài/điểm (điểm 6) và trung bình là 11,3 loài/điểm.

Hệ số tương đồng Sorrensen tại các điểm nghiên cứu dao động từ 0,10 (giữa điểm 11 và 17) đến 0,82 (giữa điểm 14 và 17 ) và trung bình là 0,28 (bảng 2).

Hệ số tương đồng giữa điểm 11 và 17 đạt giá trị nhỏ nhất vì môi trường giữa hai điểm này có sự khác nhau lớn nhất. Điểm 17 là điểm có nền đáy chủ yếu là đá và cát mịn, độ đục thấp nên rất thuận lợi cho rong biển phát triển. Trong khi đó, điểm 11 là điểm có nền đáy là cát bùn, thường xuyên phơi bãi nên rong biển rất khó tồn tại và phát triển. Tại hai điểm 14 và 17 , hệ số này đạt cực đại vì các điều kiện tự nhiên tại hai điểm tương đối đồng nhất (nhiệt độ, chất đáy, độ trong của nước biển ...).

Mặc dù diện tích đầm Nại không lớn, các điểm khảo sát cách nhau không xa, môi trường tương đối dồng nhất nhưng hệ số tương đồng giữa các điểm đạt giá trị tương đối thấp $(0,28)$. Điều này có thể giải thích rằng, vùng ven bờ đầm Nại đang bị san lấp, xây kè bờ nên địa hình bị chia cắt (thậm chí nhiêu chỗ bị vùi lấp hoàn toàn) đã ảnh hưởng đến số lượng loài tại mỗi điểm khảo sát dẫn tới số lượng loài bị thay đổi, kéo theo hệ số tương đồng giảm theo và đạt giá trị thấp.

Bảng 2. Hệ số tương đồng của rong biển giữa các điểm khảo sát

\begin{tabular}{|c|c|c|c|c|c|c|c|c|c|c|c|c|}
\hline Điểm & 1 & 2 & 6 & 7 & 9 & 11 & 13 & 14 & 15 & 17 & 18 & 20 \\
\hline 20 & 0,24 & 0,22 & 0,22 & 0,52 & 0,16 & 0,11 & 0,36 & 0,44 & 0,26 & 0,28 & 0,26 & \\
\hline 18 & 0,15 & 0,24 & 0,14 & 0,20 & 0,38 & 0,15 & 0,33 & 0,21 & 0,37 & 0,63 & & \\
\hline 17 & 0,68 & 0,21 & 0,11 & 0,30 & 0,44 & 0,10 & 0,22 & 0,82 & 0,27 & & & \\
\hline 15 & 0,26 & 0,40 & 0,35 & 0,30 & 0,72 & 0,46 & 0,33 & 0,42 & & & & \\
\hline 14 & 0,23 & 0,31 & 0,12 & 0,24 & 0,30 & 0,12 & 0,26 & & & & & \\
\hline 13 & 0,26 & 0,36 & 0,16 & 0,25 & 0,36 & 0,22 & & & & & & \\
\hline 11 & 0,18 & 0,26 & 0,40 & 0,23 & 0,17 & & & & & & & \\
\hline 9 & 0,27 & 0,25 & 0,21 & 0,20 & & & & & & & & \\
\hline 7 & 0,66 & 0,20 & 0,43 & & & & & & & & & \\
\hline 6 & 0,21 & 0,18 & & & & & & & & & & \\
\hline 2 & 0,31 & & & & & & & & & & & \\
\hline 1 & & & & & & & & & & & & \\
\hline
\end{tabular}

\section{Biến động thành phần theo mùa}

Qua kết quả khảo sát vào mùa khô (tháng 7 năm 2013 và 5 năm 2014) và mùa mưa (tháng 10 năm 2013), chúng ta thấy rằng, trong tổng số 47 loài đã phát hiện được, vào mùa khô có 38 loài và mùa mưa có 39 loài (trong số đó có 32 loài xuất hiện cả trong mùa mưa và mùa khô, chiển tỷ lệ $68,0 \%$ ). Số lượng loài tại các điểm khảo sát mùa khô dao động từ 3 (điểm số 13) đến 17 (điển số 9) và trung bình là 9,16 . Trong khi đó, chỉ số này vào mùa mưa là 3 (điểm 17) đến 17 (điểm 6) và trung bình là 7,75 . Như vậy, sự biến động về thành phần loài theo mùa tại đầm Nại không lớn. Nguyên nhân chính do đầm Nại nằm trong khu vực ít mưa nhất trong cả nước, lượng nước mưa cũng không đáng kể và đầm Nại hầu như không có nguồn nước ngọt đổ vào trong khi nhiệt độ các tháng biến đổi ít và trong giới hạn phát triển của rong biển nên số lượng loài gần như giống nhau.

\section{Phân bố sâu}

Căn cứ vào thủy triều tháng 7/2013 và tháng 4/2014 tại Cam Ranh, chúng ta thấy, trong số 47 loài rong biển tại đầm Nại, có 31 loài phân bố trên vùng triều và 32 loài ở vùng 


\section{Đàm Đức Tiến}

dưới triều (trong đó có 18 loài phân bố ở cả vùng triều và dưới triều). Số lượng loài phân bố ở vùng triều và dưới triều không có sự sai khác do mực nước trong đầm không lớn, thủy triều nhật triều không đều nên sự phân bố theo chiều sâu gần như không có sự sai khác.

\section{Đặc trung $k h u$ hệ}

Qua bảng 1 áp dụng tỷ số Cheney để tính toán đặc trưng khu hệ rong biển cho vùng nghiên cứu cho thấy rẳng, tỷ lệ giữa tổng số loài rong đỏ và rong lục chia cho số loài rong nâu là $(15+22) / 5=7,4>6$. Với kết quả này khu hệ rong biển ở đầm Nại mang tính nhiệt đới.

\section{KẾT LUẬN}

Tại đầm Nại đã phát hiện được 47 loài rong biển, thuộc 4 ngành là rong lam (Cyanophyta), rong đỏ (Rhodophyta), rong nâu (Phaeophyta) và rong lục (Chlorophyta). Trong số đó, tảo lam có 5 loài, chiếm $10,6 \%$ tổng số loài; rong đỏ có 15 loài chiếm $31,9 \%$; rong nâu có 5 loài, $10,6 \%$ và nhiều nhất là rong lục có 22 loài chiếm $46,9 \%$ tổng số loài.

Số lượng loài tại các điểm nghiên cứu dao động trong khoảng 3 loài/điểm (điểm 17) đến 20 loài/điểm (điểm 6) và trung bình là 11,3 loài/điểm. Trong số 47 loài, vào mùa khô có 38 loài và mùa mưa có 39 loài (trong số đó có 32 loài xuất hiện cả trong mùa mưa và mùa khô, chiển tỷ lệ $68,0 \%)$. Hệ số tương đồng Sorrensen tại các điểm nghiên cứu dao động từ 0,10 (giữa điểm 11 và 17 ) đến 0,82 (giữa điểm 14 và 17 ) và trung bình là 0,28 .

Trong số 47 loài rong biển tại đầm Nại, có 31 loài phân bố trên vùng triều và 32 loài ở vùng dưới triều (trong đó có 18 loài phân bố ở cả vùng triều và dưới triều).

Khu hệ rong biển đầm Nại mang tính nhiệt đới.

Lời cảm ơn: Tác giả xin gửi lời cảm ơn tới Đề tài "Nghiên cứu giải pháp phục hồi hệ sinh thái đầm, hồ ven biển đã bị suy thoái ở khu vực miền Trung", Mã số KC.08.25/11-15 đã hỗ trợ kinh phí thực hiện nội dung nghiên cứu này.

\section{TÀI LIỆ THAM KHẢO}

1. Trung tâm Khoa học Tư nhiên và Công nghệ Quốc gia, 1994. Chuyên khảo biển Việt Nam. Tập IV. Nguồn lợi sinh vật và các hệ sinh thái biển. 530 tr.

2. Uỷ ban Khoa hoc \& Kỹ thuật Nhà nước, 1980. Quy phạm tạm thời điều tra tổng hợp biển (phần Rong biển). Nxb. Khoa học và Kỹ thuật, Hà Nội. 205 tr.

3. English, S., Wilkinson, C., and Baker, V., 1997. Manual for survey of tropical marine resources. $2^{\text {nd }}$ Edition. H. P. Australian Institute of Marine Science. 390 p.

4. Nguyễn Hũu Dinh, Huỳnh Quang Năng, Trần Ngọc Bút, Nguyê̂n Văn Tiến, 1993. Rong biển Việt Nam (phần phía Bắc). Nxb. Khoa học và Kỹ thuật, Hà Nội. 364 tr.

5. Phạm Hoàng Hộ, 1969. Rong biển Việt Nam (phần phía Nam). Trung tâm Học liệu, Sài Gòn. 558 tr.

6. Cribb, A. B., 1983. Marine algae of the souhern Great Barrier Reef (No. 2). Australian coral reef society.

7. Zeng, C., 1983. Common seaweeds of China. Science Press.

8. Feldmann, J., 1937. Les algues marines de la côte des Albères. I-III. Cyanophycées, Chlorophycées, Phaéophycées. Revue Algologique 9: 141(bis)-148(bis); 149-335, 67 figs, pls 8-17.

9. Ho, P. H., 1962. Contribution a l'étude du peuplement du littoral rocheux du Vietnam (Sud). Annls Fac Sci. Saigon, 1962, 249-350.

10. Bộ tu lệnh Hải quân, 2012. Bảng thủy triều năm 2012. Tập II. 83 tr.

11. Bộ tu lệnh Hải quân, 2013. Bảng thủy triều năm 2013, Tập II. 83 tr.

12. Cheney, D. P., 1977. R \& C/P: A new and improved ratio for comparing seaweed floras. Journal of Phycology 13/(suppl.):12. 
Thành phần loài và phân bố của rong biển ...

\title{
SPECIES COMPOSITION AND DISTRIBUTION OF SEAWEEDS AT NAI LAGOON, NINH THUAN PROVINCE
}

\author{
Dam Duc Tien
}

\author{
Institute of Marine Environment and Resources-VAST
}

\begin{abstract}
This paper presents the status of species composition and distribution of seaweeds at Nai lagoon, Ninh Thuan province. From 2013 to 2014, seaweed samples from 12 sites at Nai lagoon were collected. The result shows that, there are 47 species of marine seaweeds, belonging to four phyla: Cyanophytes (Cyanophyta), Rhodophytes (Rhodophyta), Phaeophytes (Phaeophyta) and Chlorophytes (Chlorophyta). Among them, five species were classified in Cyanophyta (comprising 10.6\% of total species); fifteen species in Rhodophyta (31.9\%); five species in Phaeophytea (10.6\%) and twenty two species in Chlorophyta (46.9\%). The number of species at each site is significantly different, ranges from 3 species (site number 17) to 20 (site number 6) and average value is 11.3 species per site. The number of species in dry season is 38 and in rainy season is 39, and 32 species appear in both seasons. The coefficient index fluctuates from 0.10 (site number 11 and 17) to 0.82 (14 and 17). Among 47 species, 31 species distribute in the littoral zone and 32 species distribute in sub-littoral zone. Marine algal flora in Nai lagoon is represented by tropical characteristics.
\end{abstract}

Keywords: Nai lagoon, species, distribution, composition, seaweed. 